\title{
Lymphocyte Subsets and Mitogen Induced Proliferation in Adjuvant Arthritis. Part III. Numbers and Functions of $T$ Lymphocytes in Spleen
}

\author{
Ching-Lin Tsai and Tang-Kue Liu \\ Department of Orthopaedic Surgery, School of Medicine, \\ National Taiwan University, Taipei, Taiwan, Republic of \\ China
}

TsaI, C.-L. and LIU, T.-K. Lymphocyte Subsets and Mitogen Induced Proliferation in Adjuvant Arthritis. Part III. Numbers and Functions of $T$ Lymphocytes in Spleen. Tohoku J. Exp. Med., 1992, 166 (3), 289-296 — The changes and the possible roles of splenic $\mathrm{T}$ lymphocyte subpopulations in highresponder Long-Evans (LE) rats and low-responder Sprague-Dawley (SD) rats with induced adjuvant arthritis (AA) were investigated. Total splenic T lymphocytes of both strains did not change significantly after the adjuvant injection. However, LE rats exhibited an increase in percentage of helper $\mathrm{T}$ cells and helper/suppressor $\mathrm{T}$ cell ratio, whereas SD rats expressed a decrease in the ratio with concomitant increase of suppressor $\mathrm{T}$ cells. This observation suggested that an imbalance of $\mathrm{T}$ lymphocyte ratio not only existed in the peripheral blood as reported by other investigators, but also existed in the spleen of rats with AA. In vitro measurement of phytohemagglutinin (PHA) responses of splenic $\mathrm{T}$ lymphocytes revealed an increased PHA response in LE but a markedly decreased PHA response in SD. Both LE and SD rats showed decreased response to concanavalin A (Con A) stimulation. We concluded that PHA response, as an index of helper $\mathrm{T}$ cell function, coincided with the development of AA and may be responsible for the immunoregulation of the disease. The increased proliferation of suppressor $\mathrm{T}$ cell in SD rats may also be significant in regulating the immune response to AA.— adjuvant arthritis; helper/suppressor $\mathrm{T}$ cell ratio; PHA ; Con A ; spleen.

Adjuvant arthritis (AA) induced in rats by complete Freund's adjuvant (CFA) shares many characteristics of rheumatoid arthritis (RA) (Stoerk et al. 1954 ; Pearson 1956, 1959; Pearson and Wood 1959; Silverstein and Sokoloff 1960 ; Pearson et al. 1961; Kourounakis and Kapusta 1976). Lymphocytes are important mediators and effectors in tissue inflammatory diseases. Previous investigations have shown that $\mathrm{T}$ lymphocyte and the imbalance of $\mathrm{T}$ cell subpopulations were involoved in the induction and immunoregulation of AA

Received September 4, 1991 ; revision accepted for publication January 27, 1992.

Correspondence: Dr. Ching-Lin Tsai, Department of Orthopaedic Surgery, National Taiwan University Hospital, 7 Chung-Shan South Road, Taipei, Taiwan, R.O.C. 
(Dumonde 1971; Williams et al. 1973; Biberfeld et al. 1979). Selective depletion of suppressor $\mathrm{T}$ cell by thymectomy or irradiation enhances the severity of $\mathrm{AA}$, and depletion of helper/inducer $\mathrm{T}$ cell would decrease the severity of the disease (Rosenthale and Capetola 1982). The importance of splenic suppressor T cells also were demonstrated in animal models (Kourounakis and Kapusta 1974, 1976).

Release and interaction of activated monocytes and pro-inflammatory substances such as interleukin, prostaglandin, and eicosanoid may exacerbate or alleviate hyperimmune condition through B cell function (Browning 1987). Macrophages with supernatant or lymphocytes from arthritic rats inhibit the induction of splenic suppressor $\mathrm{T}$ cell activity as measured by mitogenic responses to concavanalin (Binderup 1983). Monocytes, as the fundamental and central elements in the complex inflammatory response, may influence diseases at its fundamental levels of cellular regulation. Suppressor $\mathrm{T}$ cells, concanavalin A (Con A)-activated $\mathrm{T}$ cells, were found to suppress both $\mathrm{T}$ and $\mathrm{B}$ cell responses (Dwyer and Johnson 1981) ; therefore, decrease or hypoactivity of splenic suppressor $\mathrm{T}$ cell might disturb the normal immunoregulation and thus induce the inflammatory process. Thus, a defective induction of splenic suppressor $\mathrm{T}$ cell activity may be correlated to the pathogensis of AA.

Previous studies have evaluated the immunological mechanisms of AA with peripheral blood, lymph nodes, thymus, and other immunological organs. However, the immunological role of spleen in the pathogenesis of $\mathrm{AA}$ is unclear and is not frequently studied.

In order to have an evaluation of spleen in AA, we investigated the numbers and the ratio of $\mathrm{T}$ cell subpopulations in spleen and the in vitro response of splenic $\mathrm{T}$ cells to phytohemaggultinin and Con A. Attempts were made to correlate the pathogenesis of AA, changes of lymphocyte numbers and activity in LE and SD rats.

\section{Materials and Methods}

Animals

Seventy 10-week-old inbred female rats of both LE and SD strains were supplied by the Central Laboratory of Experimental Animals, College of Medicine, National Taiwan University. They were housed in cages, fed with a standard laboratory food, and given free access to water.

\section{Induction of arthritis}

Rats were inoculated with $0.1 \mathrm{ml} \mathrm{CFA} \mathrm{(6} \mathrm{mg} \mathrm{killed} \mathrm{tubercle} \mathrm{bacilli/ml,} \mathrm{Difco,} \mathrm{Detroit,}$ MI, USA) into the left hind foot pad. Rats developed nodules on ears or tail, and front paw swelling were determined to be arthritic. Ten rats were sacrificed at each time point on days $0,4,7,11,14,21$, and 28 for the subsequent preparation of mononuclear cells, mitogenic response, and $\mathrm{T}$ cell classification by monoclonal antibodies. 


\section{Preparation of mononuclear cells in spleen}

Spleen cell suspensions were prepared under aseptic conditions by mincing and filtration through sterile gauze into RPMI- 1640 culture medium ( $10 \%$ heat-inactivated fetal calf serum, 100 I.U. penicillin and $100 \mu \mathrm{g}$ streptomycin per $\mathrm{ml}$ ). The supernatant, which contained mostly mononuclear cells, was aspirated and centrifuged. The cells were then washed 3 times, each with Hanks' balanced salt solution (HBSS) and centrifuged at $400 \mathrm{~g}$ for 5 min. The final mixture contained $2 \times 10^{6}$ cells $/ \mathrm{ml}$ for mitogen culture and $5 \times 10^{6}$ cells $/ \mathrm{ml}$ for subpopulation enumeration. Viability was always greater than $95 \%$ as judged by the trypan blue exclusion (Tennant 1964).

\section{Proliferation of mononuclear cells}

Phytohemagglutinin (PHA ; M-form, Gibco, Grand Island, NY, USA) was lyophilized and diluted to $1: 10$; concanavalin A (Con A ; Difco, Detroit, MI, USA) was diluted to 1 : 5,000 . An aliquot of $0.1 \mathrm{ml}$ of mononuclear cell suspension prepared from spleen was cultured for 3 days in $0.1 \mathrm{ml}$ diluted PHA and RPMI- 1640 medium containing $10 \%$ heat-inactivated calf serum, 100 I.U. penicillin, and $100 \mu \mathrm{g}$ streptomycin per ml (Boldt et al. 1975). Cells of the control group were cultured in the same medium without the added mitogen. The harvested cells were further incubated with $20 \mu \mathrm{l}$ of ${ }^{3} \mathrm{H}$-thymidine $(100 \mu \mathrm{Ci}$ ${ }^{3} \mathrm{H}$-thymidine per $\mathrm{ml}$ ) for $18 \mathrm{hr}$ and the labeled cells were collected onto the filter paper of the cell collector (Bellco, Vineland, NJ, USA). Total counts per minute (cpm) was then determined using a liquid scintillation counter (Packard, Downers Grove, IL, USA). The difference of the averaged cpm botween the experimental group and the control group was calculated to be PHA-induced proliferative response of splenic cells. Proliferation of T cells to Con A stimulation was also demonstrated by the techniques as described for PHA.

\section{Enumeration of $T$ cell subpopulation defined by monoclonal antibodies}

Mouse monoclonal antibodies, reactive with total $\mathrm{T}$ lymphocyte (clone W3/13), "helper/inducer" T lymphocyte (W3/25), and "suppressor/cytotoxic" T lymphocyte (OX8), were purchased from Seralab (Cambridge, UK). Fluorescein-conjugated anti-mouse goat immuoglobulin G was obtained from Cooper Biomedical (Malvern, PA, USA). The tests were performed according to the method of Reinherz et al. (1979) with some modification. Five $\mu$ l of the reconstituted W3/13 antibody solution was added to $0.2 \mathrm{ml}$ of the prepared mononuclear cell suspension and incubated at $4{ }^{\circ} \mathrm{C}$ for $30 \mathrm{~min}$. The cells were then washed 3 times, and $100 \mu \mathrm{l}$ of fluoresein-conjugated anti-mouse goat IgG were added to the cells. One drop of PBS was added to the mixture after 3 washings. The cell suspension was mounted on a fluorescent slide and sealed with a glass cover. Under the fluorescent microscope (Olympus, filter 515), 100 lymphocytes were counted and those cells showing fluorescene were counted and defined as $\mathrm{W} 3 / 13^{+}$cells. The $\mathrm{W} 3 / 25^{+}$and $\mathrm{OX} 8^{+}$cells were counted with the same method describod above.

\section{Statistics}

The results were given as mean \pm s.E.. The significance of the difference between groups was calculated by Student's $t$-test.

\section{Results}

\section{Percentage of helper $T$ lymphocytes and PHA response}

Percentage of helper T cells and PHA response increased in LE rats after the injection, when compared to that in the SD rats $(p<0.01)$. The percentage of helper $\mathrm{T}$ cells in SD decreased only on the 4 th day, but its Con A response was decreased throughout the course. In general, LE rats exhibited higher percentage 

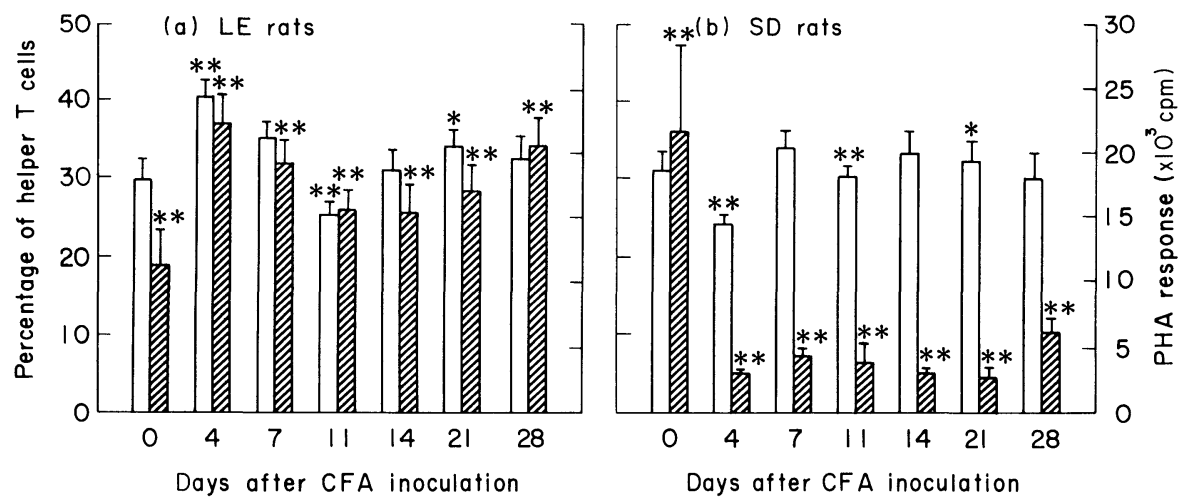

Fig. 1. Percentage of helper T cells $(\square)$ and PHA-induced response $(\mathbb{Z})$ in $\mathrm{LE}$ (a) and SD (b) rats. Values are expressed as mean \pm s.E.. $\quad n=10$ at each time intervals. ${ }^{*}$ and $* *$ indicate $p<0.05$ and $p<0.01$, respectively, between LE and SD). CFA, complete Freund's adjuvant.

of helper T lymphocytes as well as higher PHA response (Fig. 1).

\section{Percentage of suppressor $T$ cells and Con $A$ response}

Compared to SD rats, LE rats showed lower percentage of suppressor $\mathrm{T}$ cells in this study $(p<0.01)$ (Fig. 2). Throughout the study, the percentage of suppressor $\mathrm{T}$ cells in LE decreased after the adjuvant injection, whereas increased percentage was observed in SD from day 7 to day 11. Both LE and SD rats demonstrated suppressed response to Con A stimulation in the arthritic rats but no significant difference was observed between two strains (data not shown).

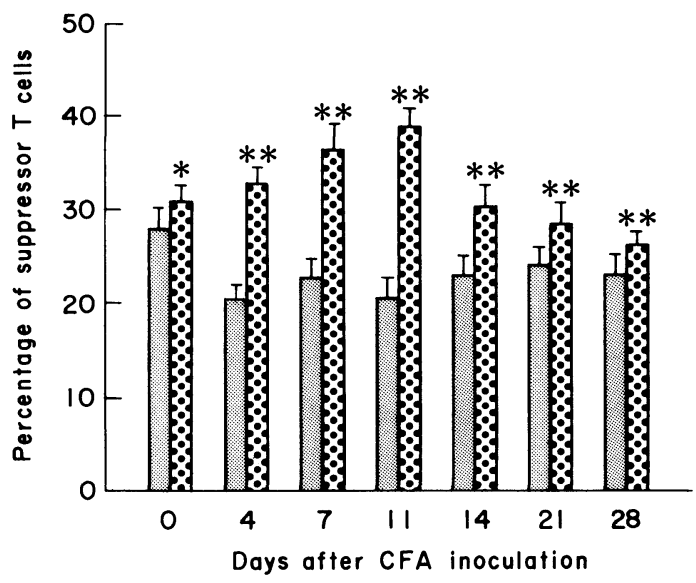

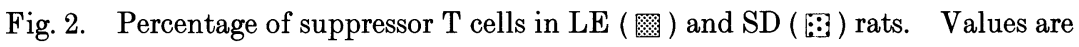
expressed as mean \pm S.E.. $n=10$ at each time intervals. *and **indicate $p<0.05$ and $p<0.01$, respectively, between $\mathrm{LE}$ and SD. CFA, complete Freund's adjuvant. 

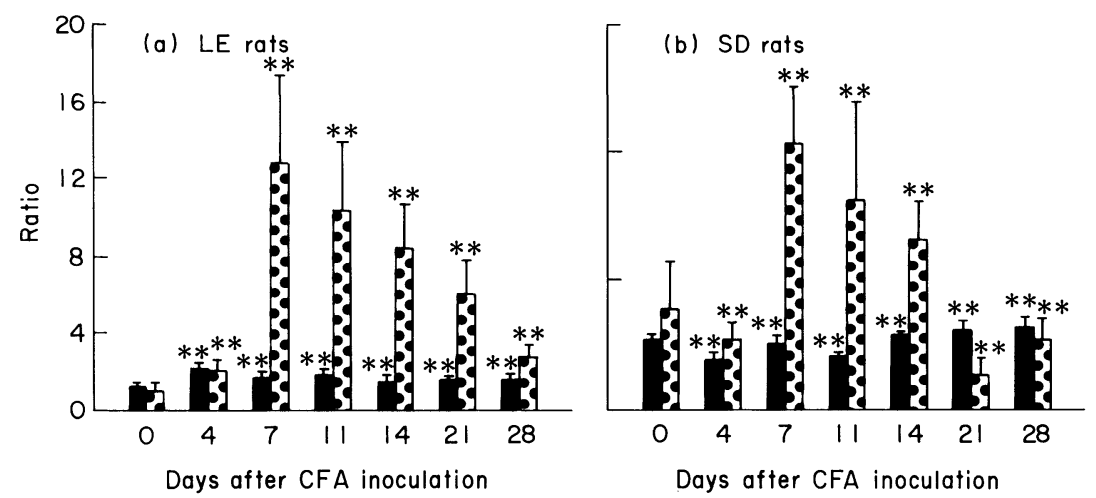

Fig. 3. Comparative analysis of helper/suppressor ratio ( $\mathbf{a})$ and PHA/Con A ratio ( $\boldsymbol{Q}$ ) in LE (a) and SD (b) rats. Values are expressed as mean \pm s.e. ( $n=10$ at each time point). CFA, complete Freund's adjuvant. *and **indicate $p<0.05$ and $p<0.01$, respectively, compared between LE and SD rats.

\section{Helper/suppressor $T$ cell ratio and $\mathrm{PHA} /$ Con $A$ ratio}

Ratio of helper and suppressor $\mathrm{T}$ cells was obtained by dividing percentages of two T cell subpopulations. Similarly, responses to two mitogenic stimulations, PHA and Con A, were calculated and the division was defined as the PHA/Con A ratio. Helper/suppressor T cell ratio and PHA/Con A ratio of LE rats showed marked increases after the injection. The increased ratios in LE rats were significantly higher than those in SD (Fig. 3). These ratios varied in SD rats.

\section{Discussion}

Adjuvant arthritis, as an animal model of human rheumatic arthritis, is a polyarthritis induced by complete Freund's adjuvant containing Mycobacterium butyricum or by type II collagen (Pearson et al. 1961 ; Trentham et al. 1980 ; Klareskog et al. 1983). Adjuvant arthritis is regarded as a cell-mediated immunological disease because it can be passively transferred by means of sensitized intact lymphoid cells but not by antisera between highly inbred rats (Waksman and Wennersten 1963; Pearson and Wood 1964).

Suppressor T cell hypofunction has been implicated in the pathogenesis of the autoimmune disease such as active systemic lupus erythematosus, juvenile rheumatoid arthritis, and early active rheumatoid arthritis (Abdou et al. 1981). In our study, significantly lower percentage of suppressor $\mathrm{T}$ cells was observed in LE rats, the high responder of AA; however, SD rats, the low responder of AA, exhibited increased percentage of suppressor $\mathrm{T}$ cells. These results suggested that $\mathrm{LE}$ rats had diminished function and numbers of suppressor $\mathrm{T}$ cells and were more susceptible to AA. AA can be enhanced by thymectomy, low dose irradiation, and cyclophosphamide (Kayashima et al. 1976), which selectively deplete a 
certain population of $\mathrm{T}$ lymphocytes being thymus-dependent, short-lived, and radiosensitive. These properties are consistent with those of suppressor $\mathrm{T}$ cells, thus indicating the possible role of suppressor T cells in AA. Suppressor T cells are thought to have inhibitory effects on both $\mathrm{T}$ and $\mathrm{B}$ cell function, which might provide SD rats with resistance to AA. Suppressor T cells appear after adjuvant injection in the spleen of rats and the subsequent transfer of splenic cells suppresses adjuvant arthritis (Ogawa and Tsunematsu 1988).

Splenic suppressor cells can also suppress the mitogenic responses of normal splenic lymphocytes (Kourounakis and Kapusta 1974). In our study, SD rats exhibited diminished PHA and Con A responses of splenic lymphocytes during the active phase of AA. LE rats had similar decrease of Con A response but showed increases in PHA response. Increased ratio of PHA and Con A proliferation in LE rats was observed after the adjuvant injection and persisted throughout the course of induced AA. This suggested that $\mathrm{PHA} / \mathrm{Con} \mathrm{A}$ ratio may be an index of susceptibility for AA. According to our previous study, PHA response correlated highly with the percentage of helper T cells (Tsai 1988) and Con A response correlated with the percentage of suppressor $\mathrm{T}$ cells. One might argue the validity of helper/suppressor $\mathrm{T}$ cell ratio as representation of $\mathrm{PHA} / \mathrm{Con} \mathrm{A}$ ratio. Functions of helper and suppressor $\mathrm{T}$ cells could not be determined simply from the their percentages or ratio. In fact, the helper/suprressor ratio varies greatly in rheumatoid arthritis according to the previous reports (Christian and Paget 1976), and increased moderately in LE rats as observed in our study. Therefore, persisted elevation of $\mathrm{PHA} / \mathrm{Con} \mathrm{A}$ ratio observed in the high responder $\mathrm{LE}$ rats suggested that $\mathrm{PHA} / \mathrm{Con} \mathrm{A}$-induced response of lymphocytes may be an index of disease susceptibility for adjuvant arthritis as well as rheumatoid arthritis.

In this study, LE, the high responder, had increased helper $\mathrm{T}$ cells but decreased suppressor $\mathrm{T}$ cells. On the other hand, SD rats, the low responder, showed increases of suppressor $\mathrm{T}$ cells and moderate decrease of helper $\mathrm{T}$ cells after adjuvant injection. Both LE and SD rats had decreased Con A response but only SD rats had decreased PHA response. Ratio of two mitogenic responses may be an index of disease susceptibility for AA since the high responder (LE) showed significantly higher PHA/Con A ratio. Nevertheless, PHA response of other tissues such as peripheral blood, lymph nodes, and thymus should be further evaluated and compared with present results to confirm our hypothesis.

\section{References}

1) Abdou, N.I., Lindsley, H.B., Racela, L.S., Pascual, E. \& Hassanein, K.M. (1981) Suppressor $\mathrm{T}$ cell dysfunction and anti-suppressor cell antibody in active early rheumatoid arthritis. J. Rheumatol., 8, 9-18.

2) Biberfeld, G., Nilsson, E. \& Biberfeld, P. (1979) T lymphocyte subpopulations in synovial fluid of patients with rheumatic disease. Arthritis Rheum., 22, 978-982.

3) Binderup, L. (1983) Lymphocyte-macrophage co-operation during induction of 
T-suppressor cell activity in rats with adjuvant arthritis. Ann. Rheum. Dis., 42, 687692.

4) Boldt, D.H., MacDermott, R.P. \& Orolan, E.P. (1975) Interaction of plant lectins with purified human lymphocyte populations: Binding characteristics and kinetics of proliferation. J. Immunol., 114, 1532-1536.

5) Browning, J. (1987) Interferons and rheumatoid arthritis: Insight into interferon biology? Immunol. Today., 8, 372-374.

6) Christian, C.L. \& Paget, S.A. (1976) Rheumatoid arthritis. In : Immunological Diseases, 3rd edition, edited by M. Samter, Little, Brown \& Co., Boston, pp. 10611076.

7) Dumonde, P.A. (1971) Rheumatoid arthritis as a disorder of cell-mediated immunity. In: Rheumatoid Arthritis: Pathogenetic Mechanism and Consequences in Therapeutic., edited by W. Muller, H.G. Harwerth \& K. Fehr, Academic Press, New York, pp. 447-457.

8) Dwyer, J.M. \& Johnson, C. (1981) The use of concanavalin A to study the immunoregulation of human T cells. Clin. Exp. Immunol., 46, 237-249.

9) Kayashima, K., Koga, T. \& Onoue, K. (1976) Role of T lymphocytes in adjuvant arthritis. I. Evidence for the regulatory function of thymus-derived cells in the induction of the disease. J. Immunol., 117, 1878-1882.

10) Klareskog, L., Holmdahl, R., Larsson, E. \& Wigzell, H. (1983) Role of T lymphocytes in collagen II induced arthritis in rats. Clin. Exp. Immunol., 51, 117125.

11) Kourounakis, L. \& Kapusta, M.A. (1974) Effect of Freund's adjuvant on the mitogenic response of rat lymphocytes. Ann. Rheum. Dis., 33, 185-189.

12) Kourounakis, L. \& Kapusta, M.A. (1976) Restortation of diminished T-cell function in adjuvant-induced disease by methotrexate. Evidence for two populations of splenic T-cell suppressors. J. Rheumatol., 3, 346-354.

13) Ogawa, H. \& Tsunematsu, T. (1988) Participation of suppressor-inducer cells in the suppression of adjuvant arthritis by transfer of spleen cells expanded by $\mathrm{T}$ cell growth factor. Clin. Exp. Immunol., 72, 476-480.

14) Pearson, C.M. (1956) Development of arthritis, periarthritis, and periostitis in rats given adjuvants. Proc. Soc. Exp. Biol. Med., 91, 95-101.

15) Pearson, C.M. (1959) Development of arthritis in the rat following injection with adjuvant. In : Mechanisms of Hypersensitivity., edited by J.H. Shaffer, G.A. LoGrippo \& M.W. Chase, Little Brown \& Co., Boston, pp. 647-671.

16) Pearson, C.M. \& Wood, F.D. (1959) Studies of polyarthritis and other lesions induced in rats by injection of mycobacterial adjuvant. I. General clinical and pathological characteristics and some modifying factors. Arhtirits Rheum., 2, 440-459.

17) Pearson, C.M. \& Wood, F.D. (1964) Passive transfer of adjuvant arthritis by lymph node or spleen cells. J. Exp. Med., 120, 547-560.

18) Pearson, C.M., Waksman, B.H. \& Sharp, J.T (1961) Studies of polyarthritis and other lesions induced in rats by injection of mycobacterial adjuvants. V. Changes affecting the skin and mucous membranes: Comparison of the experimental process with human disease. J. Exp. Med., 113, 485-510.

19) Reinherz, E.L., Parkman, R., Rappeport, J., Rosen, F.S. \& Schlossman, S.F. (1979) Aberrations of suppressor T cells in human graft-versus-host disease. N. Engl. J. Med., 300, 1061-1068.

20) Rosenthale, M.E. \& Capetola, R.J. (1982) Adjuvant arthritis: Immunopathological and hyperalgesic features. Fed. Proc., 41, 2577-2582.

21) Silverstein, E. \& Sokoloff, L. (1960) Periarthritis produced in rats with Freund' adjuvants. Arthritis Rheum., 3, 485-495.

22) Stoerk, H.C., Bielinski, T.C. \& Budzilovich, T. (1954) Chronic polyarthritis in rats injected with spleen in adjuvants. Am. J. Pathol., 30, 616. (Abstract) 
23) Tennant, J.R. (1964) Evaluation of trypan blue technique for determination of cell viability. Transplantation, 2, 685-694.

24) Trentham, D.E., McCune, W.J., Susman, P. \& David, J.R. (1980) Autoimmunity to collagen in adjuvant arthritis in rats. J. Clin. Invest., 66, 1109-1117.

25) Tsai, C.L. (1988) Adjuvant arthritis in the Long-Evans and Sprague-Dawley rats : A comparative study. J. Formosan Med. Assoc., 87, 700-706.

26) Waksman, B.H. \& Wennersten, C. (1963) Passive transfer of adjuvant arthritis in rats with living lymphoid cells of sensitized donors. Int. Arch. Allergy Appl. Immunol., 23, 129-139.

27) Williams, R.C., Jr., DeBoard, J.R., Mellbye, O.J., Messner, R.P. \& Lindström, F.D. (1973) Studies of T- and B-lymphocytes in patients with connective tissue diseases. J. Clin. Invest., 52, 283-295. 